\section{The Apprentice highlights good oral health in children}
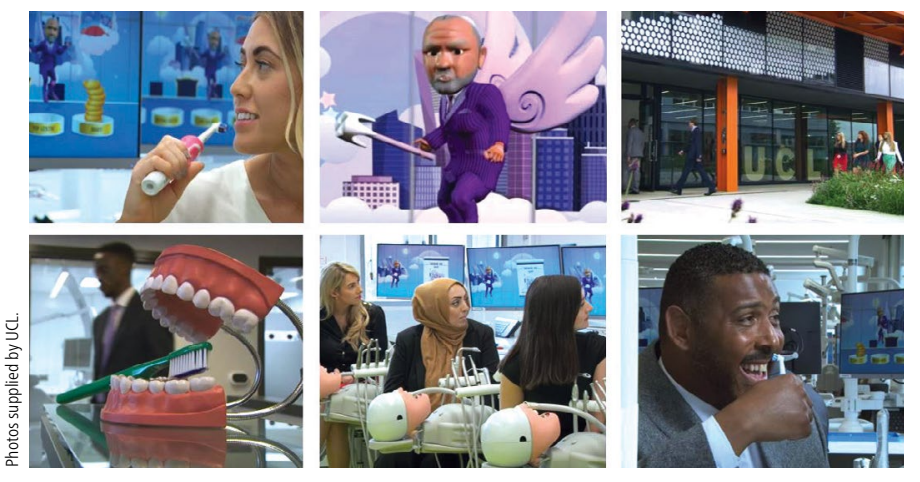

Oral healthcare took centre stage in a recent episode of the BBC's The Apprentice which aired on 13 January. The episode, filmed in the UCL Eastman Dental Institute's new cutting-edge facilities, as well as other parts of UCL, saw two teams tasked with designing and marketing an electric toothbrush and accompanying app to encourage children aged between six to eight to brush their teeth.

A group of children gave their verdict on the toothbrushes and app while industry experts shared their thoughts on how marketable the products might be. Spoiler alert - there was a winner - and perhaps it is unsurprising.

Programmes such as The Apprentice attract large audiences and aside from being entertaining can offer the opportunity to engage the public in aspects of oral health - which, as indicated in the programme, have a large business market. More importantly, as indicated by Stephen Porter, Director of UCL Eastman: 'it highlighted the need for good oral health in children to ensure their wellbeing throughout their lives'.

The episode is available to view via BBC iPlayer.

\section{FROM THE ARCHIVE}

\section{Dental masks}

This Letter to the Editor of the BDJ was published in 1933 in Volume 55.

Dear Sir, all last winter and several times during the summer I wore a simple mask when operating, and feel sure it saved me from catching innumerable colds. I think it would be an excellent thing if all dentists adopted the same idea.

Dentists don't usually stop working when they have a cold in the head, nor do patients always tell him when they have one. If, however, the mask-wearing habit becomes common, the patients would say, 'You had better wear your mask as I have a cold coming on', and the dentists also, would not inflict his microbes on his patients.

My masks are made by my nurse, simply by folding a 6 in. by 6 in. napkin in half and attaching very narrow tape to each corner. The tape is in one piece measured to fit exactly around the operator's head so that it is simple to put on without having to tie the ends.

Yours faithfully, Walter A. Wayte, Doncaster

October 23, 1933

\section{Oral health animation unveiled ahead of Chinese New Year}

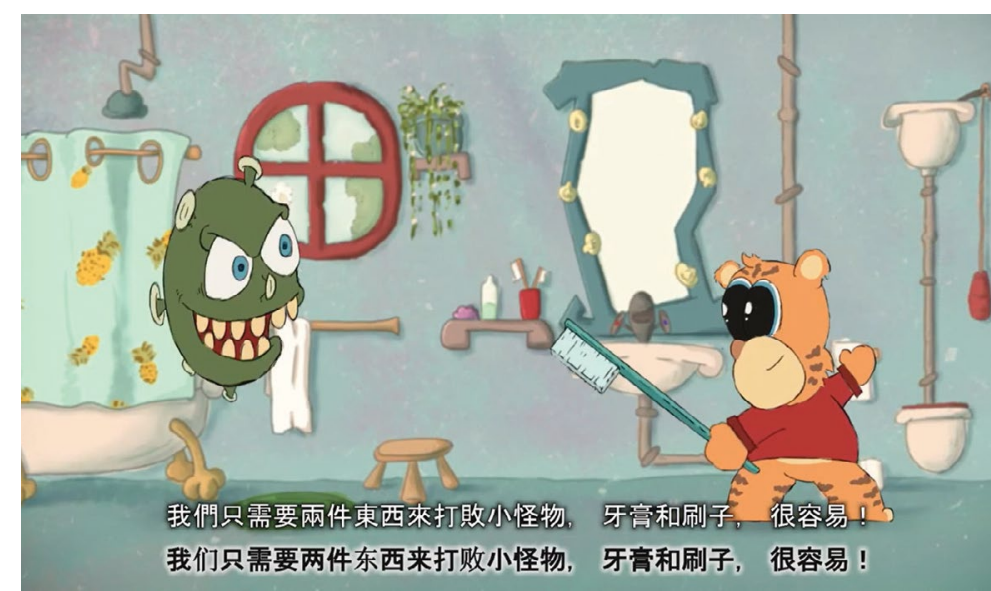

An animation promoting good oral hygiene for children was unveiled by the Lanarkshire Chinese Association (LCA) ahead of the Chinese New Year.

New College Lanarkshire graduate Ruben Fernandez created the film designed to encourage regular tooth brushing and healthy eating choices. He was commissioned by the LCA while a student of HND 3D Computer Animation at the College's Motherwell Campus.

The three-minute-long animation had its debut at the bowling pavilion of Hamilton Palace Sports Ground as part of the LCA's Annual General Meeting and Chinese New Year celebrations.

The film features a tiger cub character conceptualised by Ruben to reflect the fact that 2022 is the Year of the Tiger in the Chinese Zodiac.

Ruben, who is originally from Spain and now lives in Blantyre, said: 'I felt so good when I finished the project and seeing that the Association love the final product is a bonus point!

'I really enjoyed animating the character - this is the stage when you give it life and imagine his personality, how he speaks, and how he acts.'

Lecturer Scott McKenzie, HND 3D Computer Animation Course Leader, said: 'Ruben Fernandez's stunningly-professional animated short will help to improve the quality of life and wellbeing of children of Lanarkshire's Chinese community.

'Ruben's educational animation promotes oral health and hygiene in a manner that is humorous, attractive to a young audience, and beautifully executed.'

The project is funded by the Scottish Government through its Oral Health Community Challenge Fund, which is providing $£ 35,810$ over three years to improve oral health amongst infants and families in the Chinese community in Lanarkshire.

To watch the animation, visit: https://www.youtube.com/ watch? $\mathrm{v}=$ S9PeJEMc1mE\&feature $=$ youtu.be. 